Article

\title{
Numerical Deformation Analysis of Reinforced Lightweight Aggregate Concrete Flexural Members
}

\author{
Darius Bacinskas ${ }^{1, *}$, Deividas Rumsys ${ }^{1}$ and Gintaris Kaklauskas ${ }^{1}$ \\ 1 Department of Reinforced Concrete Structures and Geotechnical Engineering, Vilnius Gediminas Technical \\ University - Vilnius TECH, Sauletekio av. 11, LT-10223 Vilnius, Lithuania; darius.bacinskas@vilniustech.lt; \\ deividas.rumsys@vilniustech.lt; gintaris.kaklauskas@vilniustech.lt \\ * Correspondence: darius.bacisnkas@vilniustech.lt; Tel.: +370-674-23 717
}

\begin{abstract}
In the modern construction industry, lightweight aggregate concrete (LWAC) is often used in the production of load-bearing structural members. LWAC can be up to $40 \%$ lighter by volume in comparison to normal strength concrete. On the other hand, the lack of adequate numerical models often limits the practical application of innovative building materials, such as lightweight concrete, in real projects. This trend is due to the uncertainties in design standard methods and calculation errors, the level of which is generally unacceptable to civil engineers in terms of safety and reliability. In the present paper, a comparative numerical deformation analysis of a full-scale bridge deck slab and girder has been carried out. Using the physical model proposed by the authors and the finite element software ATENA, the deformations of full-scale lightweight and traditional reinforced concrete elements under short-term effects of permanent and variable loads was compared. Depending on the safety and serviceability limit requirements, it was found that the amount of longitudinal reinforcement in lightweight reinforced concrete elements can be reduced compared to normal reinforced concrete elements with the same parameters. The results of the numerical analysis show that the deformation analysis model proposed by the authors can be a reliable tool for the design of lightweight concrete flexural members by selecting the optimum geometrical and reinforcement parameters limited by the stiffness condition.
\end{abstract}

Keywords: lightweight aggregate concrete; reinforced concrete; slab; bridge girder; curvature; short-term loading; tension stiffening; constitutive model; numerical modelling.

\section{Introduction}

In the modern construction industry, lightweight aggregate concrete (LWAC), which can be up to $40 \%$ lighter by volume, is often used in the production of load-bearing structures in addition to normal strength concrete. For the production of structural lightweight concrete, natural or artificial lightweight aggregates are used in addition to heavy aggregates (sand, gravel, crushed stone) [1]. Artificial aggregates also include secondary raw materials, the use of which for concrete mixes has increased recently ([2]). The use of structural lightweight concrete for structural members has many advantages: reduced amount of reinforcement required, smaller cross-sections of elements, the possibility of constructing higher-rise buildings and lower material costs for the installation of foundations ([4,5]). These trends also reduce the overall cost of the building. The use of lightweight concrete instead of normal concrete can improve the performance of structures. Lightweight concrete has better thermal and acoustic insulation properties than normal concrete, which significantly reduces the energy consumption in buildings constructed of lightweight concrete during their operation ([6-8]). Real et al. (2016) [9] found that the use of lightweight concrete instead of normal concrete in the load-bearing structures of European buildings would result in a $15 \%$ reduction in thermal energy consumption.

In addition to these advantages, lightweight concrete has better durability properties [10] higher frost resistance, fire resistance and seismic loading - compared to normal concretes. This has 
led to the widespread use of lightweight concrete in many countries around the world for the construction of high-span bridge decks ([11]) and for the construction of multi-storey buildings ([12]). On the other hand, the increasing design requirements for advanced concrete structures, the increasing intensity of external mechanical effects and the aggressiveness of the surrounding environment highlighted the need for adequate serviceability models for the analysis of reinforced concrete (RC) structures. Reinforced concrete is an exceptional structural material because of two aspects: the extent of its practical use and the complexity of its mechanical behaviour. The latter characteristic is attributed to such phenomena as concrete cracking, shrinkage and creep effects, tension stiffening, etc. [13]. The relatively low tensile strength and cracking resistance of concrete can be identified as one of the major structural concerns.

A large number of analytical and numerical techniques for serviceability analysis of traditional RC elements have been proposed and presented to the engineering community [14-16]. However, there are relatively few universal approaches dedicated to deformational analysis of reinforced LWAC members [1].

Recently, the authors have proposed a constitutive model for the assessment of flexural stiffening of reinforced LWC beams subjected to short-term loading [17]. Further research included a comparative analysis of curvature calculations using analytical code methods EN1992-1 [18] and ACI 318-19 [19], as well as a numerical analysis using the constitutive model of cracked tensile lightweight concrete proposed by the authors [20]. The analysis was carried out on a sample of experimental data of 51 lightweight reinforced concrete members obtained under five experimental programs published in the literature. A comparison of theoretical and experimental results showed that the most accurate predictions are obtained using numerical analysis and the constitutive model proposed by the authors.

It should be noted that the lack of adequate numerical models often limits the practical application of innovative building materials, such as lightweight concrete, in real projects [21]. This trend is due to the uncertainties in design standard methods and calculation errors, the level of which is generally unacceptable to civil engineers in terms of safety and reliability. In this work, a comparative numerical deformation analysis of a full-scale bridge deck slab and girder has been carried out. Using the physical model proposed by the authors and the finite element software ATENA, the deformations of full-scale lightweight and traditional reinforced concrete elements under short-term effects of permanent and variable loads was compared. Depending on the safety and serviceability limit requirements, it was found that the amount of longitudinal reinforcement in lightweight reinforced concrete elements can be reduced compared to normal reinforced concrete elements with the same parameters. The results of the numerical analysis show that the deformation analysis model proposed by the authors can be a reliable tool for the design of lightweight concrete flexural members by selecting the optimum geometrical and reinforcement parameters limited by the stiffness condition.

\section{Numerical Model for Finite Element Analysis of LWAC Flexural Members}

Numerical inverse technique for deriving the constitutive model incorporating experimental results of reinforced lightweight concrete elements is discussed in more detail in references [1, 19, 20]. The basic aspects of the physical modelling are presented below. The methodology is based on a layered section model, which implies the successive application of the direct (curvature prediction) and inverse (constitutive modelling) approaches. The method proposed by Kaklauskas and Ghaboussi [22] was applied to constitutive modelling to obtain average stress and average strain diagrams for cracked tensile concrete. As a result, tension-stiffening diagrams with eliminated shrinkage [23-24] were obtained. The proposed model (Figure 1) is approximated by a three-curve diagram. The ascending branch of the curve represents the elastic behaviour of the reinforced concrete before cracking. Meanwhile, the horizontal line and descending branch characterise the stages of crack formation and further development, respectively. The ultimate tensile strength is $\sigma_{c t}=0.55 f_{\text {cct }}$, where $f_{\text {lct }}$ is the average tensile strength of lightweight aggregate concrete calculated according to the EC2 standard [18]. 


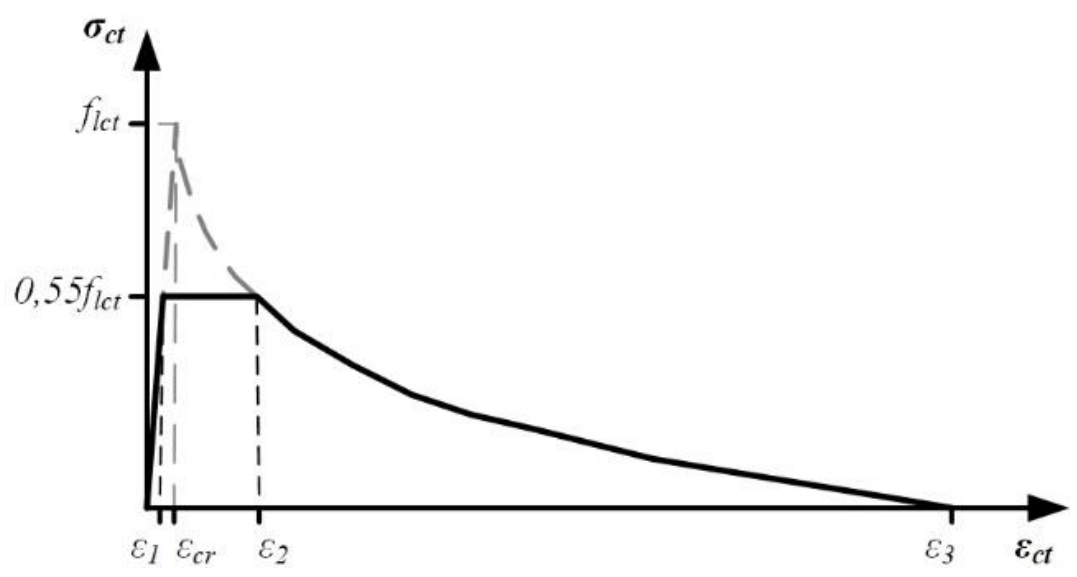

Figure 1. Tension-stiffening model of structural lightweight tensile concrete

Strain $\varepsilon 1$ is calculated according to the following formula:

$$
\varepsilon_{1}=0.55 \varepsilon_{c r}
$$

where $\varepsilon_{c r}=f_{l c t} / E_{l c m}$ is the theoretical cracking strain corresponding to the tensile strength, and Elcm is the modulus of elasticity of concrete calculated according to EC2 depending on the compressive strength of concrete.

The descending branch of the diagram is approximated by the following relationship:

$$
\sigma_{c t}=f_{l c t}\left(1-0.27 \ln \left(\frac{\varepsilon_{c t}}{\varepsilon_{c r}}\right)-0.21 \rho_{R}\right)
$$

where $\rho_{R}$ is the reinforcement perecentage [\%].

Strain $\varepsilon_{2}$ is calculated according to the following formula:

$$
\varepsilon_{2}=\varepsilon_{c r} e^{1.667-0.78 \rho_{R}}
$$

The length of the descending branch is defined by the maximal strain $\varepsilon_{3}$ corresponding to zero stress. This strain is calculated according to the following formula:

$$
\varepsilon_{3}=\varepsilon_{c r} e^{3.7-0.78 \rho_{R}}
$$

Nonlinear numerical analysis was performed using the finite element software ATENA. In most cases, two-dimensional finite element models of reinforced concrete elements were created employing constitutive models of compressive and tensile concrete and reinforcement. The behaviour of reinforcement is represented by an elastic-plastic model corresponding to the yield strength of steel and the modulus of elasticity. A linear elastic diagram was used to model the compressive concrete. The proposed constitutive model (Figure 1) was used to describe the behaviour of lightweight aggregate concrete in tension. The 3D Nonlinear Cementitious 2 User material model (based on the SBETA material model offered by ATENA) was utilized. Concrete without cracks is considered as an isotropic body and concrete with cracks as an orthotropic body. The smeared crack and fracture mechanics approaches are combined in ATENA to assess the nonlinear behaviour of reinforced concrete elements after cracking. In this study, a fixed crack model was used. The fracture mechanics approach employed in ATENA for softening behaviour is based on the crack band model. Isoparametric quadrilateral finite elements with eight degrees of freedom and four integration points were used to model the concrete beams. Reinforcement bars were modelled with truss finite elements. A typical finite element model including the support conditions of RC member is presented in Figure 2. 


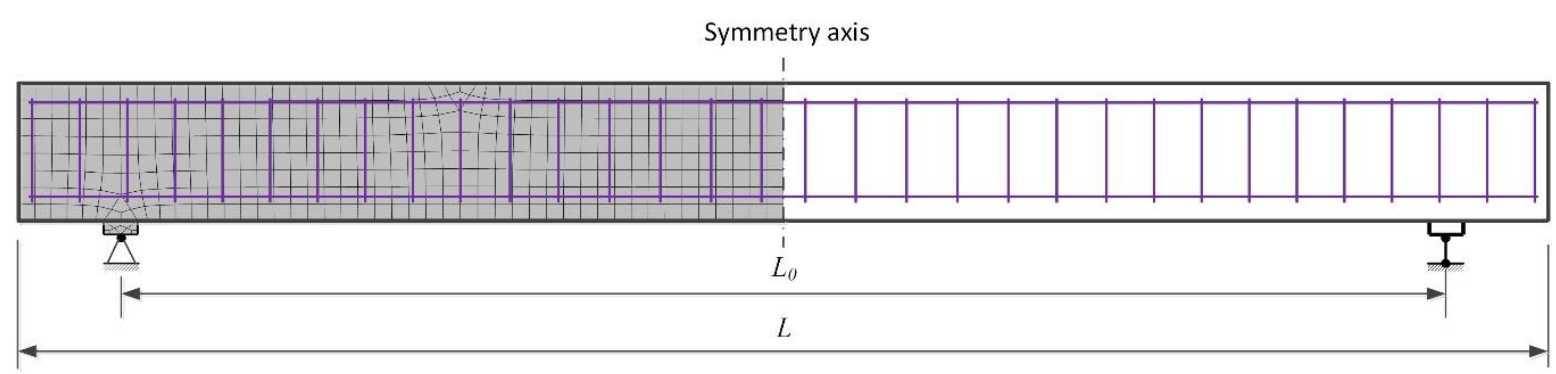

Figure 2. Finite element model and support conditions of reinforced LWAC slabs

\section{Accuracy Assessment of the Numerical Finite Element Model}

To evaluate the proposed numerical finite element model, a comparative numerical analysis of three fullscale experimental panels published by Vakhshouri [25] was carried out. The experimental program consisted of testing of three full-scale reinforced concrete slabs by short-term loading. All specimens were of rectangular section, with nominal length of $3800 \mathrm{~mm}$, span of $3500 \mathrm{~mm}$, depth of $161 \mathrm{~mm}$ and width of $400 \mathrm{~mm}$. All beams were tested by applying a uniformly distributed load using concrete blocks. Two different loading levels were selected during the test. Experimental loads were applied at the age of 14 days. The tensile reinforcement consisted of $4 \# 12 \mathrm{~mm}$ diameter bars assuring reinforcement percentage of $0.83 \%$. The concrete cover from the centroid of longitudinal reinforcement to the nearest concrete surface was $25 \mathrm{~mm}$. The specimens were cast using concrete mix with the following physical and mechanical parameters: density $-2000 \mathrm{~kg} / \mathrm{m}^{3}$, compressive strength $-31 \mathrm{MPa}$, tensile strength $-2.29 \mathrm{MPa}$.

A comparison of numerical and experimental results with respect to the bending moment curvature diagrams is presented in Figure 3. The presented comparison shows that the numerical model of reinforced lightweight concrete proposed by the authors is suitable for the deformation analysis of full-scale structures. The theoretical model provides reliable theoretical results at all stages of slab loading. The maximum discrepancy between the experimental and theoretical results at the service load $\left(M_{E k}\right)$ level does not exceed 2,5\%. The analysis of the obtained results shows that the model proposed by the authors can be a reliable tool for the analysis of real stress - strain state of lightweight reinforced concrete.

\section{Numerical Modelling of Full-Scale Reinforced LWAC Flexural Members}

This subsection describes the comparative numerical deformation analysis of the full-scale bridge deck slab and girder under short-term loading. The behaviour of full-scale lightweight and normal reinforced concrete structural elements under short-term effects of permanent and varyiable loading was compared using the proposed physical model and the finite element program ATENA. Depending on the safety and serviceability limit requirements, it was determined that the amount of longitudinal reinforcement can be reduced in lightweight reinforced concrete elements compared to normal reinforced concrete elements with the same parameters. The subject of the study is a freesupported normal and lightweight concrete bridge deck slab and girder designed according to EC2 standard [18]. The slab was designed for two different levels of characteristic variable loads, which represent the minimum and maximum values of pedestrian loads $-2.5 \mathrm{kPa}$ and $5.0 \mathrm{kPa}-$ specified in EC1 [26]. The calculated length of the slab was $6 \mathrm{~m}$ and width of $1 \mathrm{~m}$. The height of the slab was chosen taking into account the opreating variable load and the deflection limit recommendations provided in EC2 standard [18], and was of $0.3 \mathrm{~m}$. The protective concrete layer was $40 \mathrm{~mm}$. The density of normal concrete was $2300 \mathrm{~kg} / \mathrm{m}^{3}$ and the density of lightweight concrete was $1800 \mathrm{~kg} / \mathrm{m}^{3}$. The characteristic permanent load was calculated by taking into account the self weight (dead load) of the slab and deck load (10.6 $\mathrm{kPa}$ and $9.1 \mathrm{kPa}$ for normal weight and lightweight concrete respectively). 

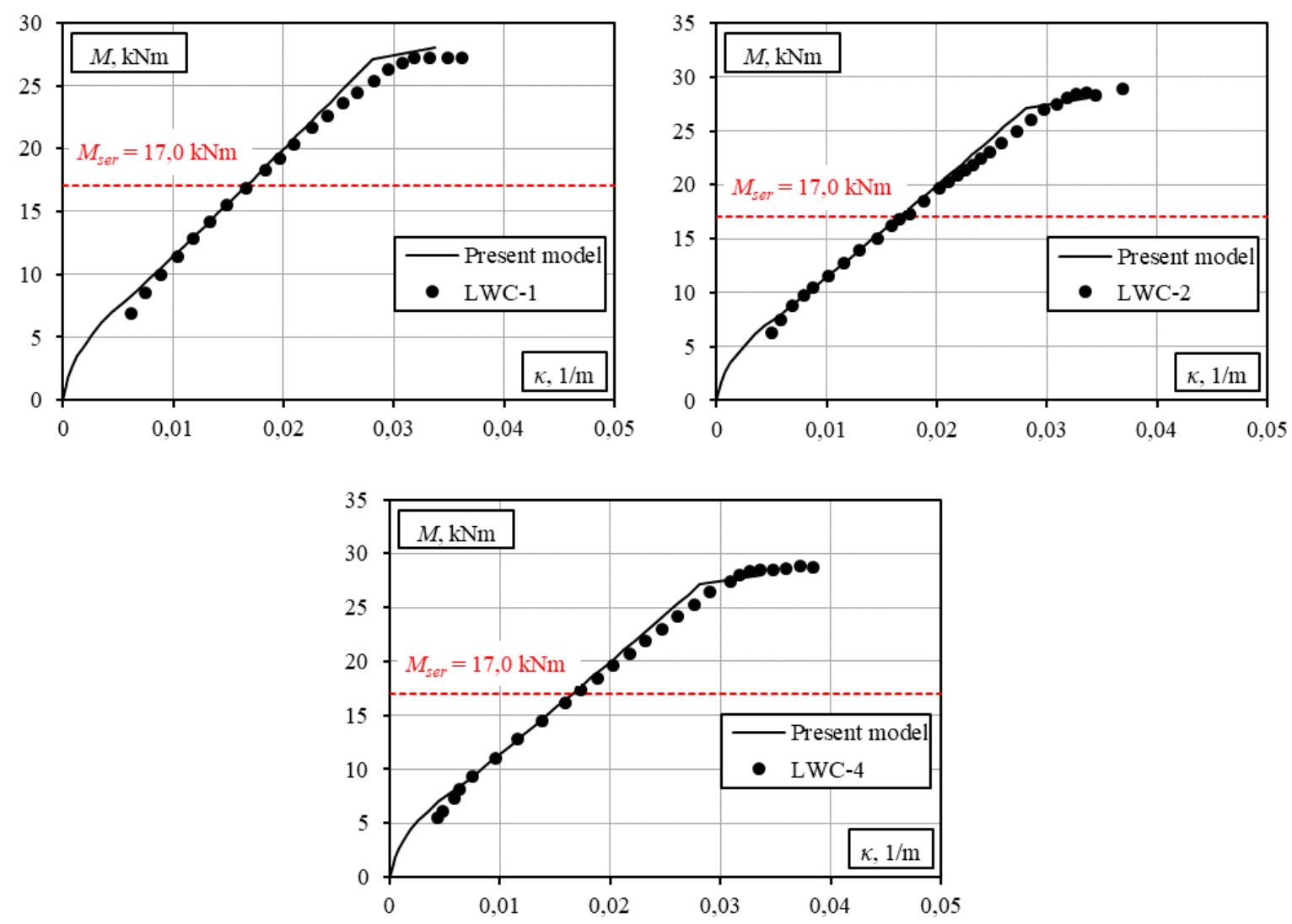

Figure 3. Comparison of theoretical and experimental moment-curvature diagrams

C30/37 concrete was used for the normal reinforced concrete elements and LC30/33 lightweight concrete with the same compressive strength was used for lightweight concrete. S500 longitudinal reinforcement was used to reinforce both elements. Transverse reinforcement was not provided. The design of normal and lightweight concrete slabs ensuring mechanical resistance in flexure and shear was performed for the set initial parameters. According to the results of the calculation of the safety limit state, normal reinforced concrete slabs subjected to variable loads of $2.5 \mathrm{kPa}$ and $5.0 \mathrm{kPa}$ were reinforced with $5 \varnothing 14 \mathrm{~mm}\left(\rho_{R}=0,3 \%\right)$ and $5 \varnothing 16 \mathrm{~mm}\left(\rho_{R}=0,4 \%\right)$ diameter bars respectively. The behavior of LWAC slabs by reducing the reinforcement intensity to $6 \varnothing 12 \mathrm{~mm}\left(\rho_{R}=0.27 \%\right)$ and $8 \varnothing 12$ $\mathrm{mm}\left(\rho_{R}=0.36 \%\right)$ was further investigated to reveal the advantages of lightweight concrete application and the reduced permanent load. The shrinkage deformations of concrete before loading were calculated according to the EC2 standard [18] methodology and for normal and lightweight concrete were $-1 \times 10^{-4}$ and $-1,14 \times 10^{-4}$ respectively. Numerical modeling was performed using the finite element program ATENA by applying the principles presented in Chapter 2 . The physical model of tensile reinforced concrete proposed by Sokolov [27] was used for normal reinforced concrete slabs and a modification of the model proposed by the authors for the LWAC slabs. The computational scheme of the slab, the main parameters and the finite element model are given in Figure 4.

The modelling of the bridge deck girder was based on similar principles. A typical girder of 16 $\mathrm{m}$ long and a T-shaped cross section with a $15.4 \mathrm{~m}$ design span used for roadway and pedestrian bridge decks was analysed. The longitudinal and transverse sections of the girder are shown in Figure 5. The girder was divided into five distinct sections based on the number and arrangement of the longitudinal tension reinforcement. The reinforcement of each section for roadway and pedestrian bridge girders is shown in Figure $5 \mathrm{c}$ and $\mathrm{d}$. 


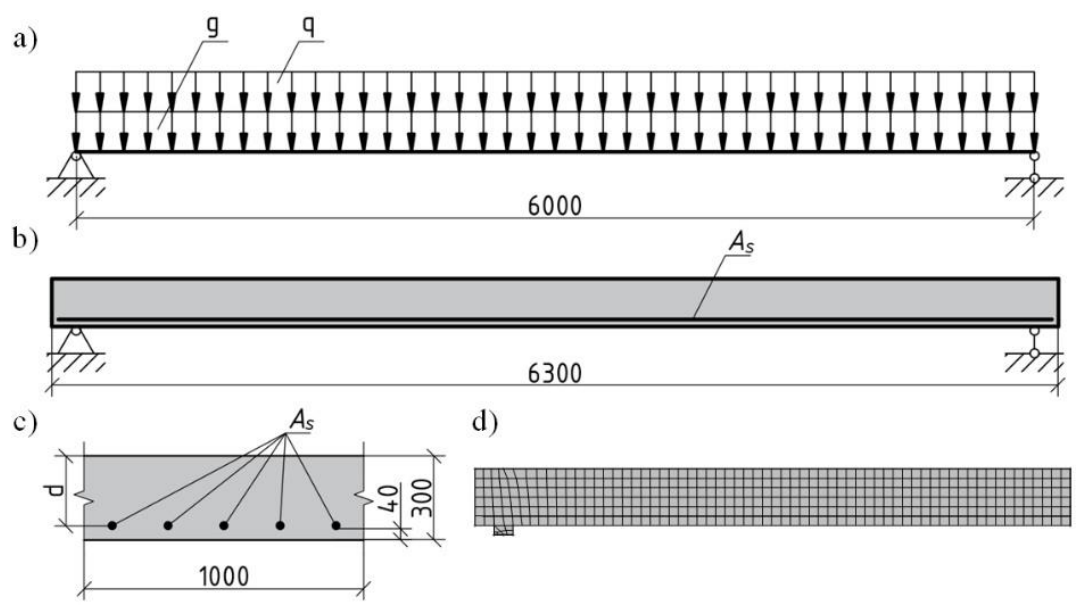

Figure 4. RC slab details: a) static scheme; b) side view; c) cross-section; d) finite element model

The roadway bridge deck girder was made of C35/45 normal weight concrete (NWC) and reinforced with S500 reinforcing bars. The girder is designed to withstand a design bending moment of $M_{R d}=2140 \mathrm{kNm}$. The characteristic bending moment due to the self-weight of the girder and the permanent load on the bridge deck was $M_{g k}=476 \mathrm{kNm}$. The percentage of reinforcement in the middle section of the girder was $2.33 \%$. LC35/38 concrete with density $\varrho=1900 \mathrm{~kg} / \mathrm{m}^{3}$ was used for lightweight concrete beams with the corresponding geometrical parameters and reinforcement. Due to the reduced self-weight, the characteristic bending moment under the permanent load for these girders decreased to $M_{g k}=407 \mathrm{kNm}$.

Pedestrian bridge girder has been designed for $5 \mathrm{kPa}$ live load. C30/37 concrete and S500 reinforcement were used for reinforced NWC beams. The longitudinal reinforcement of girders in different sections (Figure $5 \mathrm{~d}$ ) was chosen to ensure the load-bearing capacity in the normal section. LC30/33 lightweight concrete with density $\mathrm{Q}=1800 \mathrm{~kg} / \mathrm{m}^{3}$ was used for lightweight concrete beams. The characteristic bending moment caused by permanent loading due to the lower self-weight of the girder decreased from $M_{g k}=459 \mathrm{kNm}$ to $M_{g k}=389 \mathrm{kNm}$. The behavior of NWC and LWAC beams with the same reinforcement intensity was compared in the first step between the behavior of lightweight and normal concrete elements. Taking into account the reduced permanent load, the behavior of LWAC beams in the middle zone (Figure $5 \mathrm{~d}$, zones 1-2) was further investigated in the second stage by reducing the reinforcement percentage from $0.72 \%$ to $0.64 \%$. In this way, the diameter of longitudinal reinforcement of the girder examined in the second stage was changed from $\varnothing 20 \mathrm{~mm}$ to $\varnothing 18 \mathrm{~mm}$.

The influence of shrinkage strains, $\varepsilon_{c s}$, in the stage prior to loading was evaluated in the numerical analysis. The values of $\varepsilon_{c s}$ were calculated according to the EC2 design standard [18]. For roadway reinforced concrete bridge girder the following valus have been obtained: for normal concrete $-5.8 \times 10^{-5}$, for lightweight concrete $-6.2 \times 10^{-5}$. The values of shrinkage strains of pedestrian bridge girders have been selectes as follows: for normal concrete $-5.4 \times 10^{-5}$, for lightweight concrete $5.8 \times 10^{-5}$. The GID program module integrated in the finite element program ATENA was used to model the girders. The numerical model was developed using three-dimensional isoparametric finite elements with twenty-four degrees of freedom and eight integration points. Other aspects of the modeling did not differ from those used in the numerical modeling of the girders. The computersimulated girder image is given in Figure $5 \mathrm{e}$ and the division into finite elements is shown in Figure $5 f$. It should be noted that due to the uncertainties related to the prediction of the shear strength of lightweight concrete, the shear strength of the latter elements has not been assessed in the analysis presented in the section. It was assumed that the strength of normal and lightweight concrete elements was equal. The sufficient shear strength of reinforced lightweight concrete elements was confirmed by the simulation results: all elements decomposed in the normal section due to the bending moment effect. 
a)

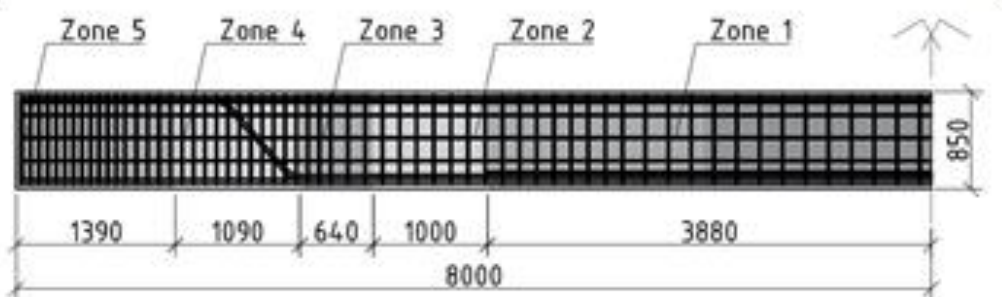

c)

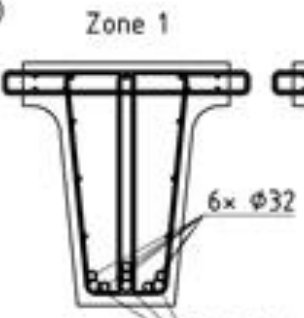

d)

Zones 1-2

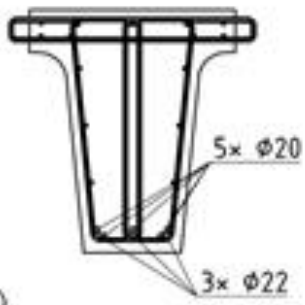

e)

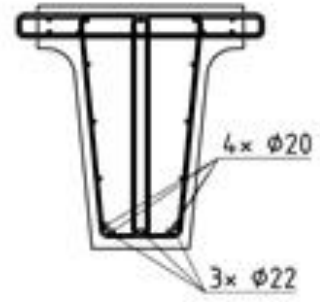

Zone 4

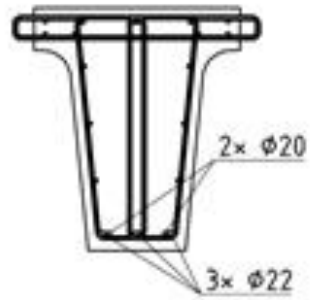

b)

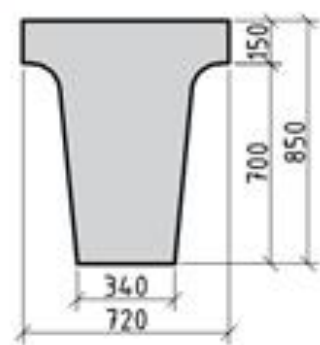

Zone 5

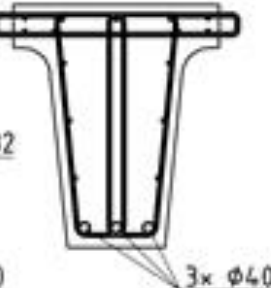

Zone 5
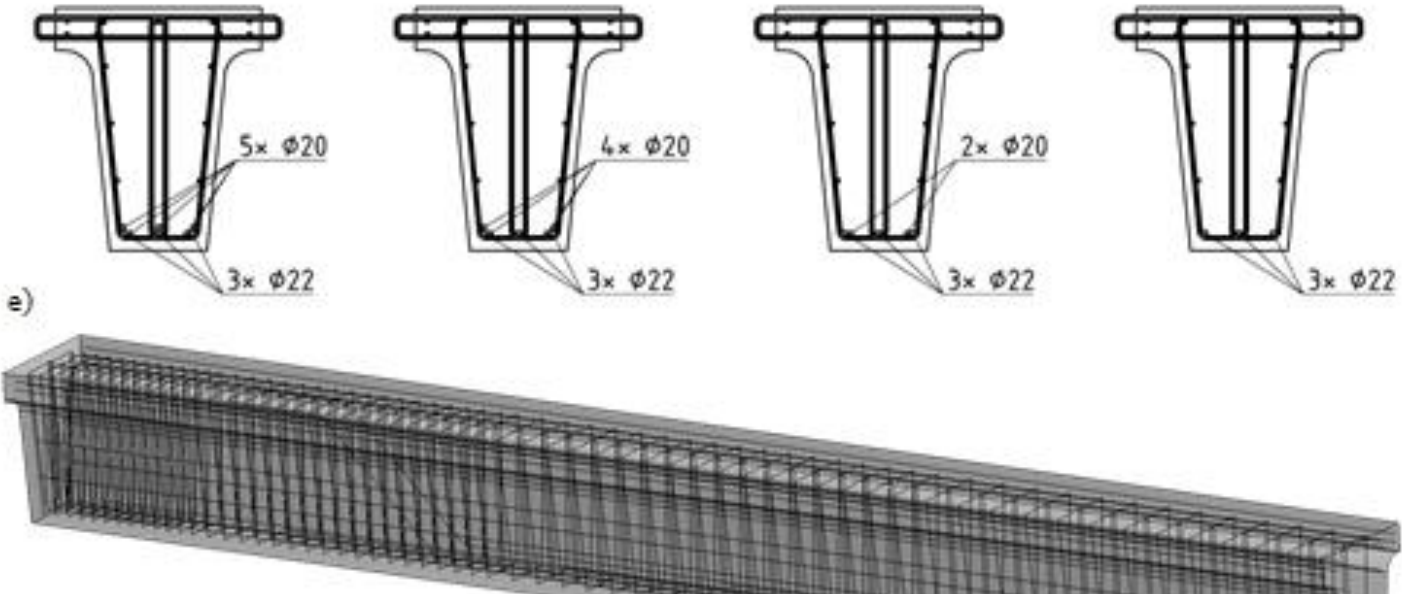

f)

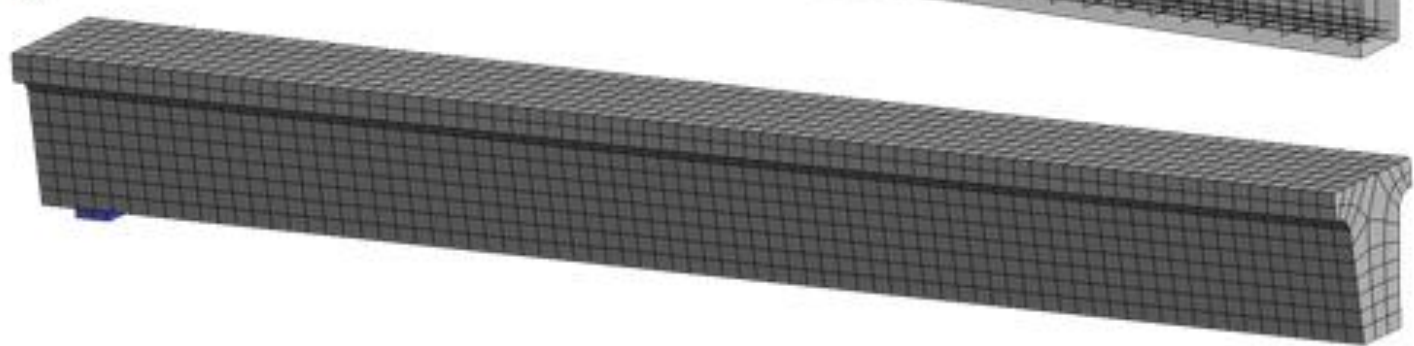

Figure 5. Reinforced concrete bridge girders used in the analysis: a) longitudinal cross section and division into reinforcing zones; b) cross section; c) reinforcing details of roadway bridge girder in different zones; d) reinforcing details of footbridge girder in different zones; e) computer model;

f) finite element model

\section{Results of Numerical Modelling}

The simulation results for normal and lightweight concrete slabs with the same parameters are shown in Figure 6. The results were compared at the level of total characteristic bending moment MEk. In bridge design practice, deflections caused by permanent loads, including long-term changes, are usually compensated by the initial deflection of structures. The stiffness of structures is usually limited by deflections caused by characteristic variable traffic loads, which in turn are limited by relative deflection limits regulated by design standards. The limitation of deflections in lightweight reinforced concrete due to its lower stiffness can be a decisive factor in the design of these structures. 

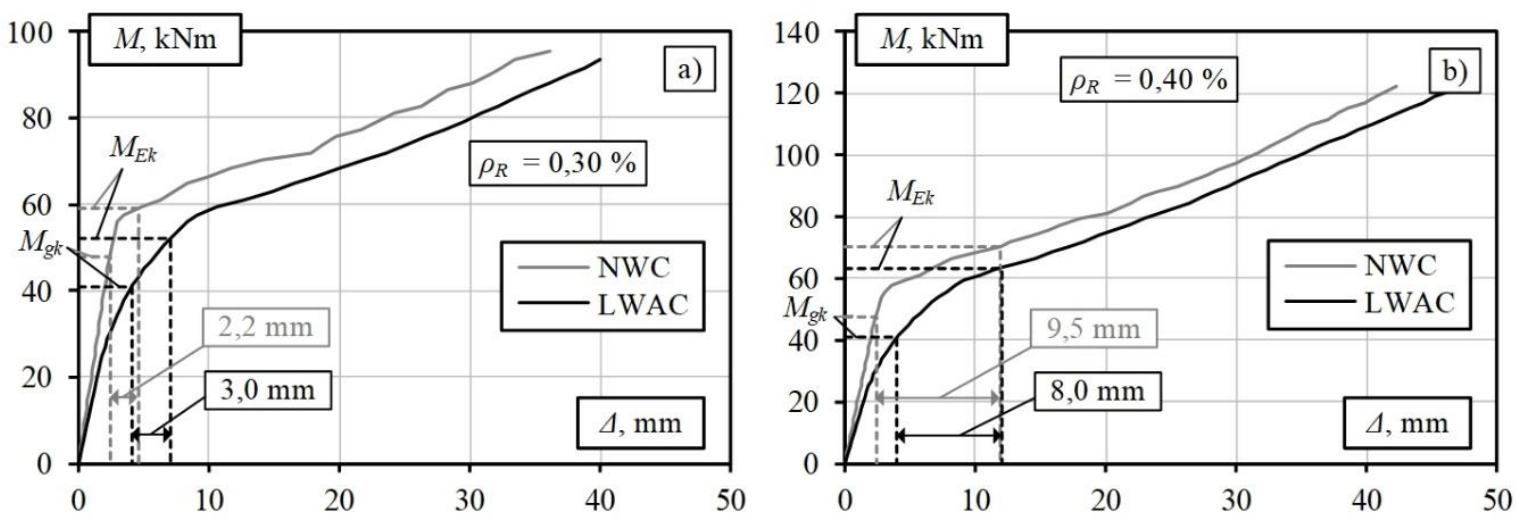

Figure 6. Results of numerical modelling of slabs

Figure 6 shows that the deflection of the LWAC slab with a reinforcement percentage of $0.30 \%$ due to the variable load $\left(\Delta_{q k}=3.0 \mathrm{~mm}\right)$ is slightly higher than that of a normal reinforced concrete slab $\left(\Delta_{q k}\right.$ $=2.2 \mathrm{~mm}$ ). In general, the deflection values for both elements are small. Slightly different trends were obtained for slabs with a reinforcement percentage of $0.40 \%$ (Figure 6). The deflection of the normal reinforced concrete slab due to the variable load is higher than that of the LWAC slab, $9.5 \mathrm{~mm}$ and $8.0 \mathrm{~mm}$ respectively. These differences can be explained by the lower total bending moment of the LWAC slabs due to the lower permanent load. The detailed calculation results are summarised in Table 1 . In this table, $M_{g k}$ is the bending moment due to the characteristic permanent load, $M_{E k}$ is the bending moment due to the characteristic total load, $M_{E d}$ is the bending moment due to the design total load, $M_{R k}$ is the element's resisting characteristic bending moment and $\Delta_{q k}$ is the deflection due to the characteristic variable load.

The lower weight of LWAC slabs can reduce the amount of longitudinal reinforcement compared to slabs of the same parameters made of normal concrete. On the other hand, the reduced stiffness of elements in this case may require consideration of deflection constraints. These values are regulated in various design standards and depend on the purpose of structures.

Table 1. Analysis results of designed slabs

\begin{tabular}{|c|c|c|c|c|c|c|c|c|}
\hline \multirow{2}{*}{ No. } & \multirow{2}{*}{$\begin{array}{c}\text { Concrete } \\
\text { type }\end{array}$} & \multirow{2}{*}{$\rho R, \%$} & \multicolumn{5}{|c|}{ Bending moments, $\mathrm{kNm}$} & \multirow{2}{*}{$\begin{array}{l}\text { Deflections } \\
\qquad \Delta_{q k}, \mathrm{~mm}\end{array}$} \\
\hline & & & $M_{g k}$ & $M_{E k}$ & $M_{g k} / M_{E k}$ & $M_{E d}$ & $M_{R k}$ & \\
\hline 1 & NWC & \multirow[b]{2}{*}{0.30} & 47.7 & 59.0 & 0.81 & 79.6 & \multirow[b]{2}{*}{95.1} & 2.2 \\
\hline 2 & LWAC & & 41.0 & 52.3 & 0.78 & 70.5 & & 3.0 \\
\hline 3 & NWC & \multirow[b]{2}{*}{0.40} & 47.7 & 70.2 & 0.68 & 94.8 & \multirow[b]{2}{*}{122.8} & 9.5 \\
\hline 4 & LWAC & & 41.0 & 63.5 & 0.65 & 85.7 & & 8.0 \\
\hline 5 & LWAC & 0.27 & 41.0 & 52.3 & 0.78 & 70.5 & 84.4 & 3.1 \\
\hline 6 & LWAC & 0.36 & 41.0 & 63.5 & 0.65 & 85.7 & 111.7 & 8.0 \\
\hline
\end{tabular}

The results of analysis of LWAC slabs with a reduced percentage of reinforcement are shown in Figure 7. The results show a small increase in the deflection value for a slab with a reinforcement percentage of $0.27 \%$ : instead of $3.0 \mathrm{~mm}$ (for the LWAC slab where $\rho_{R}=0.3 \%$ ), a deflection of $3.1 \mathrm{~mm}$ was obtained, which is acceptable from a practical point of view. Thus, the amount of longitudinal reinforcement can be reduced by $12 \%$ by designing a LWAC bridge deck slab subjected to a variable pedestrian load of $2.5 \mathrm{kPa}$. A similar trend was obtained for slab subjected to $5 \mathrm{kPa}$ (Figure $7 \mathrm{~b}$ ). The resulting deflection value remained almost unchanged and the amount of longitudinal reinforcement was reduced by $10 \%$. The results show that the higher the ratio between the moments caused by the permanent load $\left(M_{g k}\right)$ and the total load $\left(M_{E k}\right)$, the higher the efficiency of using LWAC in load- 
bearing structures, which leads to a greater saving in the amount of longitudinal reinforcement. The values of these ratios for deck slabs are given in Table 1.
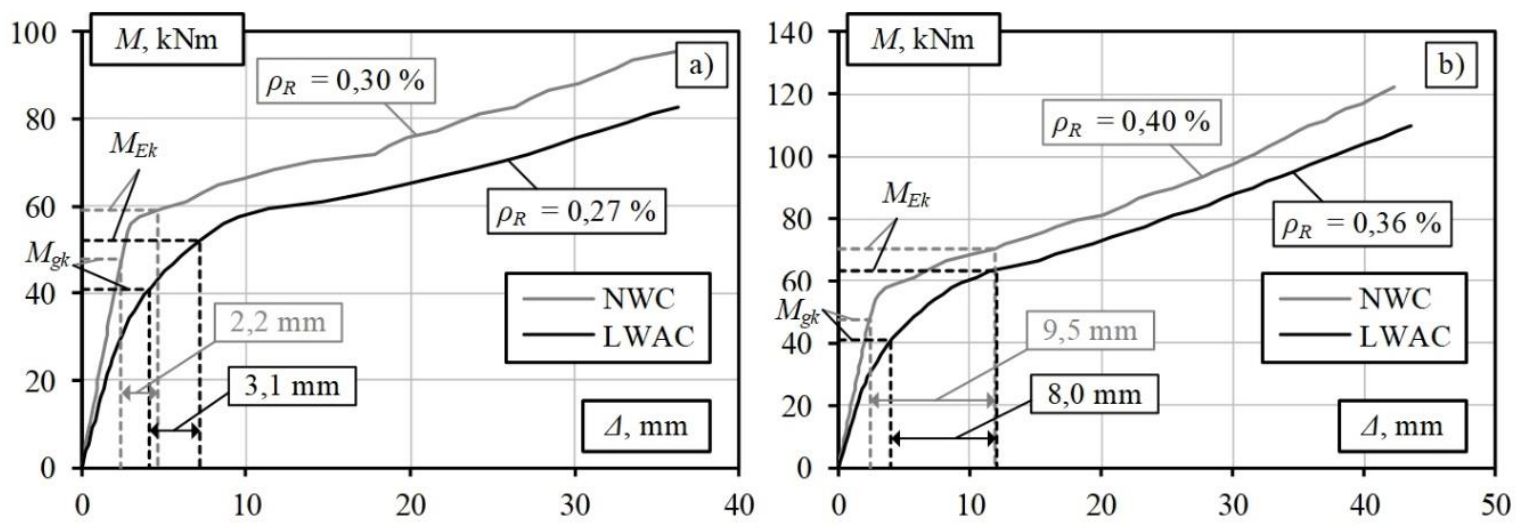

Figure 7. Modelling results of LWAC slabs with reduced reinforcement amount

The modelling results for the roadway bridge girders are presented in Figure 8a and for the pedestrian bridge in Figure $8 \mathrm{~b}$. Figure $8 \mathrm{a}$ shows that at a high percentage of reinforcement $\left(\rho_{R}=2.33 \%\right)$, the numerical deformation analysis of the same parameter elements using LWAC and NWC physical models yields approximately the same results of calculation. Slight differences in the curves of LWAC and NWC girder are related to different modulus of elasticity of these materials. The results are also in good agreement with each other because the effect of tensile concrete between the cracks on the stiffness in highly reinforced elements is insignificant. Due to this factor and the low ratio of permanent to total load (0.28-0.30, Table 2$)$, the reduction in concrete density does not have a significant structural effect.

The opposite trend was obtained for the pedestrian bridge deck girder (Figure $8 \mathrm{~b}$ ). The ratio of the permanent to the total load of these girders is 0.72-0.76 (Table 2). Similar deflection values of 16.8 $\mathrm{mm}$ and $18.1 \mathrm{~mm}$ respectfully were obtained for normal and lightweight concrete girders under variable pedestrian loading. The permanent load level and the deflection values obtained allow for a reduction in the intensity of longitudinal reinforcement of girders. The numerical modelling results for the reduced reinforcement LWAC girder of the pedestrian bridge are presented in Figure 9. The deflection value increased from $18.1 \mathrm{~mm}$ to $20.1 \mathrm{~mm}$ with a decrease in the percentage of reinforcement of the LWAC girder from $0.72 \%$ to $0.64 \%$. Considering the length of the element span, the deflection value obtained is practically acceptable. In this case, the amount of reinforcement required is reduced by $11 \%$. The results of the numerical analysis show that the deformation analysis model proposed by the authors can be a reliable tool for the design of lightweight concrete flexural members by selecting the optimum geometrical and reinforcement parameters limited by the stiffness condition.
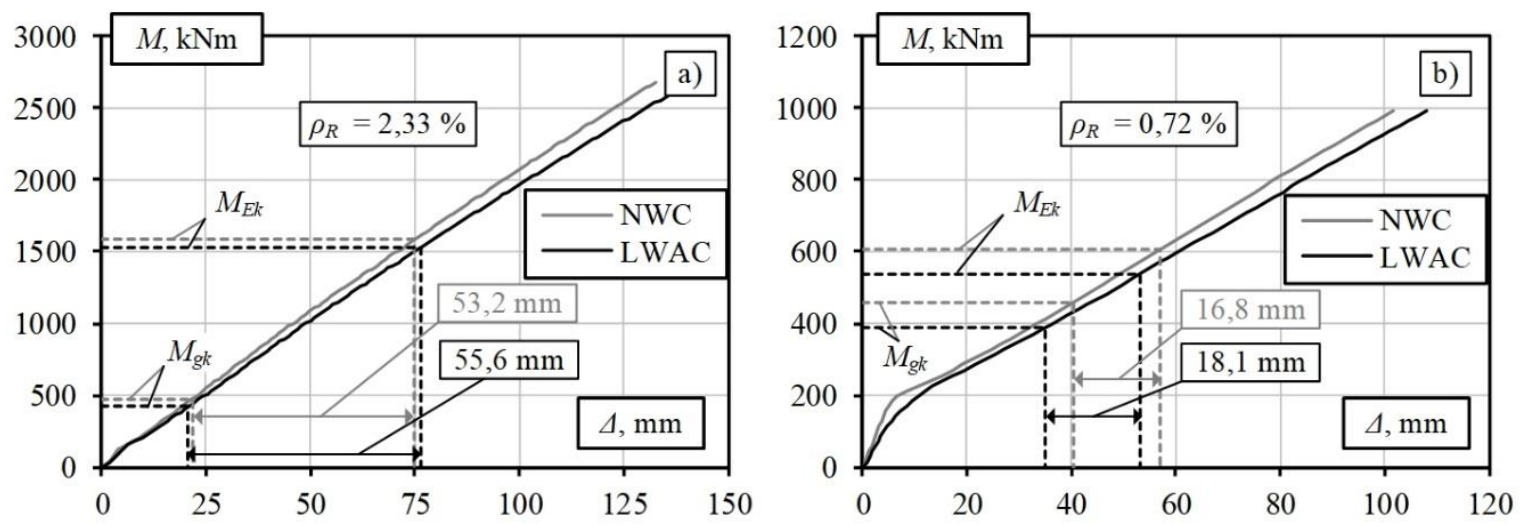

Figure 8. Modelling results of bridge girders: a) roadway bridge; b) pedestrian bridge 
Table 2. Analysis results of designed girders

\begin{tabular}{|c|c|c|c|c|c|c|c|c|}
\hline \multirow{2}{*}{ No. } & \multirow{2}{*}{$\begin{array}{c}\text { Concrete } \\
\text { type }\end{array}$} & \multirow{2}{*}{$\rho_{R}, \%$} & \multicolumn{5}{|c|}{ Bending moments, $\mathrm{kNm}$} & \multirow{2}{*}{$\begin{array}{c}\text { Deflections } \\
\Delta_{q k}, \mathbf{m m}\end{array}$} \\
\hline & & & $M_{g k}$ & $M_{E k}$ & $M_{g k} / M_{E k}$ & $M_{E d}$ & $M_{R k}$ & \\
\hline 1 & NWC & \multirow[b]{2}{*}{2.33} & 476 & 1585 & 0.30 & 2140 & \multirow[b]{2}{*}{2669} & 53.2 \\
\hline 2 & LWAC & & 421 & 1530 & 0.28 & 2066 & & 55.6 \\
\hline 3 & NWC & \multirow[b]{2}{*}{0.72} & 459 & 607 & 0.76 & 819 & \multirow[b]{2}{*}{991} & 16.8 \\
\hline 4 & LWAC & & 389 & 537 & 0.72 & 725 & & 18.1 \\
\hline 5 & LWAC & 0.64 & 389 & 537 & 0.72 & 725 & 890 & 20.1 \\
\hline
\end{tabular}

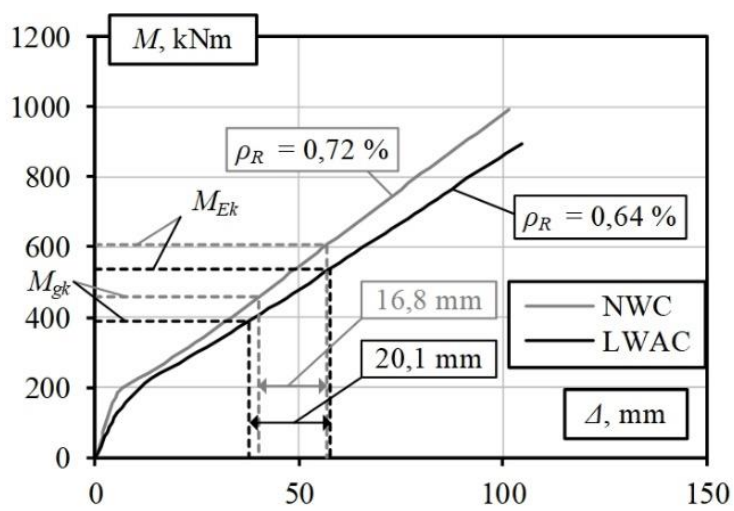

Figure 9. Results of analysis of bridge girder with reduced amount of reinforcement

\section{Conclusions}

The numerical finite element deformational analysis of reinforced normal and lightweight aggregate concrete full-scale flexural members yields the following conclusions:

1. Advanced structural lightweight aggregate concrete is a promising innovative material, the use of which in structures allows to reduce the amount of reinforcement required and the crosssections of elements. The use of lightweight concrete makes it possible to construct structures with higher geometrical parameters (e.g., height, span length, etc.) and to reduce material costs for the installation of foundations of structures.

2. The lack of adequate numerical models often limits the practical application of innovative building materials, such as lightweight concrete, in real projects. This trend is due to the uncertainties in design standard methods and calculation errors, the level of which is generally unacceptable to civil engineers in terms of safety and reliability.

3. In previous studies, the authors proposed a constitutive model for deformational analysis of reinforced lightweight aggregate concrete members. The adequacy of the model was demonstrated by comparing the theoretical results with the results of experimental studies of lightweight concrete members published in the literature. At the service load level, the proposed model obtained the most accurate results of calculations compared to traditional engineering methods.

4. The adequacy of the theoretical model was further revealed by comparing the theoretical results with experimental results of three full-scale lightweight concrete slabs. The comparative analysis showed that reliable theoretical results were obtained in all stages of slab loading. The maximum discrepancy between the experimental and theoretical results at the service load (MEk) level did not exceed 2,5\%.

5. This paper presents practical application aspects of the proposed model. A full-scale bridge deck slab and girder were chosen as the object of the study. Numerical deformation analysis was 
carried out for these elements. Using the physical model proposed by the authors and the finite element program ATENA, the deformation of full-scale lightweight and conventional reinforced concrete structural members under short-term effects of permanent and varriable loads was compared.

6. The studies showed that close deflection values were obtained for lightweight and normal concrete elements under the same levels of varrying load. However, in some cases, normal reinforced concrete elements showed higher deflections under varrying loading than lightweight concrete members of the corresponding parameters. For example, the deflection value obtained in this paper for a normal concrete slab with a reinforcement percentage of 0.40 $\%$ under varrying loading was $19 \%$ higher than that obtained for a lightweight concrete slab of the corresponding parameters. These differences can be explained by the lower total bending moment of LWAC slabs due to the lower permanent load.

7. The studies revealed that the amount of longitudinal reinforcement can be reduced in lightweight reinforced concrete elements due to the reduced permanent load (up to $12 \%$ in the present paper) compared to natural reinforced concrete elements with the same parameters.

8. The effectiveness of the application of lightweight concrete increases with the ratio of moments caused by the permanent and total loads. On the other hand, the reduced stiffness of elements may require consideration of deflection limitations. These values are regulated in various design standards and depend on the purpose of structures.

9. The use of lightweight concrete is less efficient than normal concrete, with a decreasing ratio of permanent to total moments, and an increasing percentage of reinforcement. In heavily reinforced elements $\left(\rho_{R}>2 \%\right.$ ), the effect of tensile concrete between cracks on stiffness is insignificant. In this case, the reduction in concrete density does not have a significant structural effect.

10. The results of the numerical analysis show that the deformation analysis model proposed by the authors can be a reliable tool for the design of lightweight concrete flexural members by selecting the optimum geometrical and reinforcement parameters, which are limited by the stiffness condition. The proposed model can be applied to the analysis of real lightweight concrete elements by implementing the performance-based design concept provided for in modern design standards.

Author Contributions: D. Bacinskas and D. Rumsys conceived the idea of the work. D. Rumsys analysed the experimental data. D. Bacinskas, D. Rumsys and G. Kaklauskas carried out the theoretical analysis of experimental slabs, compared the theoretical and experimental results, carried out the case study, and wrote the paper. D. Bacinskas and G. Kaklauskas made the main findings.

Funding: The study was performed within the framework of project No 09.3.3-LMT-K-712-01-0145 funded by the European Social Fund under a grant agreement with the Research Council of Lithuania (LMTLT).

Acknowledgments: The authors gratefully acknowledge the financial support provided by the European Social Fund under the grant agreement with the Research Council of Lithuania (LMTLT) for the project No 09.3.3-LMTK-712-01-0145.

Conflicts of Interest: The authors declare no conflict of interest.

\section{References}

1. Rumsys, D. Model for Deformational Analysis of Reinforced Structural Lightweight Concrete Flexural Members. PhD thesis, Vilnius Gediminas Technical University, Lithuania, 2019 (in Lithuanian).

2. Alqahtani, F.K.; Ghataora, G.; Khan, M.I; Dirar, S. Novel Lightweight Concrete Containing Manufactured Plastic Aggregate. Constr. Build. Mater. 2017, 148, 386-397, https://doi.org/10.1016/j.conbuildmat.2017.05.011.

3. Krstic, H.; Miličević, I.; Markulak, D.; Domazetović, M. Thermal Performance Assessment of a Wall Made of Lightweight Concrete Blocks with Recycled Brick and Ground Polystyrene. Buildings 2021, 11(12), 584, https://doi.org/10.3390/buildings11120584. 
4. Tanyildizi, H.; Coskun, A. The Effect of High Temperature on Compressive Strength and Splitting Tensile Strength of Structural Lightweight Concrete Containing Fly Ash. Constr. Build. Mater. 2008, 22(11), 22692275, https://doi.org/10.1016/j.conbuildmat.2007.07.033.

5. Gunduz, L.; Ugur, I. The Effects of Different Fine and Coarse Pumice Aggre-Gate/Cement Ratios on the Structural Concrete Properties without using Any Admixtures. Cem. Concr. Res. 2005, 35(9), 1859-1864, https://doi.org/10.1016/j.cemconres.2004.08.003.

6. Akeiber, H.; Nejat, P.; Majid, M.Z.A.; Wahid, M.A.; Jomehzadeh, F.; Famileh, I.Z.; Calautit, J.K.; Hughes, B.R.; Zaki, S.A. 2016. A Review on Phase Change Material (PCM) for Sustainable Passive Cooling in Building Envelopes. Renew. Sust. Energ. Rev. 2016, 60, 1470-1497, https://doi.org/10.1016/j.rser.2016.03.036.

7. Shafigh, P.; Alengaram, U.J.; Mahmud, H.B.; Jumaat, M.Z. Engineering Properties of Oil Palm Shell Lightweight Concrete Containing Fly Ash. Mater. Des. 2013, 49, 613-621, https://doi.org/10.1016/j.matdes.2013.02.004.

8. Lee, T.H.; Chua, N.; Amran, M.; Lee, Y.Y.; Kueh, A.B.H.; Fediuk, R.; Vatin, N.; Vasilev, Y. Thermal Performance of Structural Lightweight Concrete Composites for Potential Energy Saving. Crystals 2021, 11(5), 461, https://doi.org/10.3390/cryst11050461.

9. Real, S.; Gomes, M.G., Rodrigues, A.M.; Bogas, J.A. 2016. Contribution of Structural Lightweight Aggregate Concrete to The Reduction of Thermal Bridging Effect in Buildings. Constr. Build. Mater. 2016, 121, 460-470, https://doi.org/10.1016/j.conbuildmat.2016.06.018.

10. Domagała, L. Durability of Structural Lightweight Concrete with Sintered Fly Ash Aggregate. Materials 2020, 13(20), 4565, https://doi.org/10.3390/ma13204565.

11. Harmon, K.S. Norway Bridges using High Performance Lightweight Aggregate Concrete. ACI Special Publication 2004, 218, 189-198.

12. Kaklauskas, G.; Tamulènas, V.; Bado, M. F.; Bacinskas, D. Shrinkage-free tension stiffening law for various concrete grades. Constr. Build. Mater. 2018, 189(20), 736-744, https://doi.org/10.1016/j.conbuildmat.2018.08.212.

13. Demirdag, S., Gunduz, L. Strength Properties of Volcanic Slag Aggregate Lightweight Concrete for High Performance Masonry Units. Constr. Build. Mater. 2008, 22(3), 135-142, https://doi.org/10.1016/j.conbuildmat.2006.10.002.

14. Kaklauskas, G. 2017. Crack Model for RC Members Based on Compatibility of Stress-Transfer and Mean Strain Approaches. J. Struct. Eng. 2017, 143(9), 1-12, https://doi.org/10.1061/(ASCE)ST.1943-541X.0001842.

15. Ramanauskas, R. Primary Crack Spacing Model of Reinforced Concrete Elements. PhD thesis, Vilnius Gediminas Technical University, Lithuania, 2019.

16. Borosnyoi, A.; Balazs G.L. Models for Flexural Cracking in Concrete: The State of The Art. Struct. Concr. 2005, 6, 53-62, http://doi.org/10.1680/stco.6.2.53.66711.

17. Rumsys, D.; Bacinskas, D.; Kaklauskas, G.; Gribniak, V. Flexural Stiffness of Lightly Reinforced Beams Made of Structural Lightweight Aggregate Concrete. ACI Struct. J. 2019, 116(5), 17-28, http://doi.org/10.14359/51716769.

18. EN 1992-1-1:2004/A1. Eurocode 2: Design of Concrete Structures -Part 1-1: General Rules and Rules for Buildings. European Committee for Standardization, Brussels, 2015.

19. ACI 318-19. Building Code Requirements for Structural Concrete (ACI 318-19) and Commentary. ACI Committee 318, Farmington Hills, Michigan, 2019.

20. Bacinskas, D.; Rumsys, D.; Sokolov, A.; Kaklauskas, G. Deformation Analysis of Reinforced Beams Made of Lightweight Aggregate Concrete. Materials 2020, 13(1), 2020, p. 1-13, https://doi.org/10.3390/ma13010020.

21. Thienel, K.-Ch.; Haller, T; Beuntner, N. Lightweight Concrete-From Basics to Innovations. Materials 2020, 13(5), 1120; https://doi.org/10.3390/ma13051120.

22. Kaklauskas, G.; Ghaboussi, J. Stress-Strain Relations for Cracked Tensile Concrete from RC Beam Tests. J. Struct. Eng. 2001, 127(1), 64-73, https://doi.org/10.1061/(ASCE)0733-9445(2001)127:1(64).

23. Kaklauskas, G.; Gribniak, V.; Bacinskas, D.; Vainiūnas, P. Shrinkage Influence on Tension Stiffening in Concrete Members. Eng. Struct. 2009, 31(6), 1305-1312, https://doi.org/10.1016/j.engstruct.2008.10.007.

24. Kaklauskas, G.; Gribniak, V. Eliminating Shrinkage Effect from Moment Curvature and Tension Stiffening Relationships of Reinforced Concrete Members. J. Struct. Eng. 2011, 137(12), 1460-1469, https://doi.org/10.1061/(ASCE)ST.1943-541X.0000395. 
25. Vakhshouri, B. Comparative Study of the Long-Term Deflection of Conventional and Self-Compacting Concrete with Light-Weight Concrete Slabs. PhD thesis, University of Technology Sydney, Australia, 2017.

26. EN 1991-2:2003/AC:2010. Eurocode 1: Actions on Structures-Part 2: Traffic loads on bridges. European Committee for Standardization, Brussels, 2010.

27. Sokolov, A. Tension Stiffening Model for Reinforced Concrete Beams. PhD thesis, Vilnius Gediminas technical university, Lithuania, 2010. 